\title{
Collapse displacements for a mechanism of spreading-induced supports in a masonry arch
}

\author{
Simona Coccia ${ }^{1} \cdot$ Fabio Di Carlo $^{1} \cdot$ Zila Rinaldi $^{1}$
}

Received: 4 July 2014/ Accepted: 15 July 2015/Published online: 25 July 2015

(C) The Author(s) 2015. This article is published with open access at Springerlink.com

\begin{abstract}
Masonry arch systems and vaulted structures constitute a structural typology widely spread in the historical building heritage. Small displacements of the supports, due to different causes, among which subsidence of foundation systems or movements of underlying structures can lead the masonry arch to a condition of collapse because of gradual change in its geometry. This paper presents a tool, based on a kinematic approach, for the computation of the magnitude of the displacements that cause the collapse of circular arches subject to dead loads, and allows the evaluation of the related thrust value. A parametric study has been carried out in order to develop a deeper understanding of the influence of the involved parameters. In addition, analytic formulations of the maximum allowed displacement and the associated thrust are proposed. Finally, a case study related to the behavior of a masonry arch on spreading-induced abutments is undertaken and discussed.
\end{abstract}

Keywords Masonry $\cdot$ Limit analysis $\cdot$ Support displacement

\section{Introduction}

The static of masonry arches, when a finite displacement at the springing occurs, is examined in this paper. This problem is worthy of interest since small displacements of the supports in the existing masonry arches and vaults can take place due to different causes, including the subsidence

Simona Coccia

coccia@ing.uniroma2.it

1 Department of Civil Engineering, University of Rome "Tor Vergata", Rome, Italy of foundation system, viscous phenomena affecting the mortars, and movements of underlying structures. Consequently, the structure can reach a condition of collapse because of gradual changes in its geometry. A typical example is represented by arch or vault supported on piers. In this case, if displacements of the supports arise, the span increases, the rise decreases, and a growth of the arch thrust occurs, giving rise to a further movement of the springing, up to the failure condition.

The collapse analysis of masonry structures can be carried out through a static [see for example O'Dwyer (1999), Block and Ochsendorf (2007), Huerta (2008), and D'Ayala and Tomasoni (2011)] or a kinematic approach, as proposed by Como (1992, 1996, 2013), Coccia and Como (2015), and Coccia et al. (2015). Smars (2000), Ochsendorf (2002, 2006), and Romano and Ochsendorf (2010) studied the collapse behaviors of arches subjected to gravity loads and displacements of the supports, through a static approach. In Smars (2000), the domain of statically admissible movements for a chosen mechanism in a semicircular voussoir arch is identified. However, the possibility that the hinges might move as the arch supports spread apart is not investigated. Romano and Ochsendorf (2010) analyze the horizontal collapse displacements in Gothic arches considering a fixed location of the hinges. Studies by Ochsendorf $(2002,2006)$ on semi-circular arches, developed with a static approach, showed that the hinge locations are not fixed, but they may move during the displacements of the supports toward the crown of the arch.

In the present paper, the collapse behavior of arches subjected to displacements of the supports is analyzed, in an innovative way, with a kinematic approach, applied in the deformed configuration of the structure. The possibility of the variation of the hinge position is accounted for. The masonry is modeled as a no-tension material with infinite 
compression strength and sufficient friction to prevent the sliding, as introduced by Heyman (1966, 1995). In this framework, the collapse load of a masonry structure is related to a failure mechanism, kinematically compatible according to the limit analysis assumptions.

\section{State of the art: limit analysis theorems in the undeformed configuration}

The kinematic approach has been applied for arches analysis, in the undeformed configuration, according to the hypotheses of no-tension masonry material characterized by infinite strength in compression (Heyman 1966, 1995; Como 2013). Furthermore, the elastic strains are supposed to be negligible, and infinite shear strength is assumed, in order to avoid sliding failures. Consequently, in each section of the arch, compressive stresses only are allowed, and then the eccentricity of the axial load $(e)$ must be contained within the thickness ( $t$, Fig. 1a). Furthermore, due to the hypotheses of negligible elastic deformation and no-penetration of the material (infinite strength in compression), the only admissible state of deformation of the element is the rotation around one of its edge (upper or lower) or the detachment (Fig. 1b). Under these conditions, the stresses are admissible if the line of pressure is completely inside the masonry arch, and a mechanism is admissible if no internal deformation of the material takes place. The deformed shape of the structure coincides with the movement of a set of rigid bodies linked together with internal hinges.

In the following section, the limit analysis is applied to the evaluation of the minimum thrust of the arch in the undeformed configuration.

\section{Minimum thrust in the undeformed arch}

As an example, in the continuous arch reported in Fig. 2, when virtual displacements at the supports occurs, the line of pressure becomes tangent to the structure in a finite number of points. These points can be seen as internal hinges, and the structure can accommodate the span increase with a kinematically admissible mechanism. In particular, three hinges are formed, one at the extrados in the keystone and the other two at the intrados (Fig. 2a). In general, the positions of these hinges coincide with the joints, provided that the tensile strength of these sections is lower than that of the brick.

In the undeformed configuration, kinematic and static theorems can be applied to find the exact position of the hinges and the value of the minimum thrust (Como 1996, 1998, 2013). According to these theorems, the thrust in the settlement mechanism is the lowest of all the statically admissible ones (static theorem), and the highest of all the kinematically admissible ones (kinematic theorem). The thrust is statically admissible if it generates a line of pressure inside the structure (Fig. 2a), and kinematically admissible if the internal work done for a kinematically admissible virtual mechanism is equal to zero. In Fig. 2a is shown a kinematically admissible mechanism for an arch subjected to an increase of the span, and in Fig. 2b is highlighted the corresponding virtual deformed configuration.

The actual value of the thrust is the only one that is both statically and kinematically admissible.

The procedure for the evaluation of the minimum thrust is here summarized.

The application of the principle of virtual work for the admissible virtual mechanism $\delta u$, shown in Fig. 2a, leads to the equation:

$\int g \cdot \delta u_{\mathrm{v}}(x) \mathrm{d} x+\mu \cdot h \cdot \delta u=\int_{V} \sigma \cdot \varepsilon \mathrm{d} V \quad \sigma \in S, \forall \delta u \in M$

which can be written as

$$
\langle g, \delta u\rangle+\mu\langle h, \delta u\rangle=\langle\sigma, \varepsilon(\delta u)\rangle \quad \sigma \in \mathrm{S}, \forall \delta u \in M
$$

where $M$ is the class of the kinematically admissible mechanisms; $g$ is the gravity load, $\varepsilon(\delta u)$ is the strain related to the virtual displacement $\delta u ; \mu$ is the multiplier of the unitary thrust $h ; \sigma$ and $S$ are the vector and the class of the admissible stresses in equilibrium, respectively, with $g$ and $\mu t$.

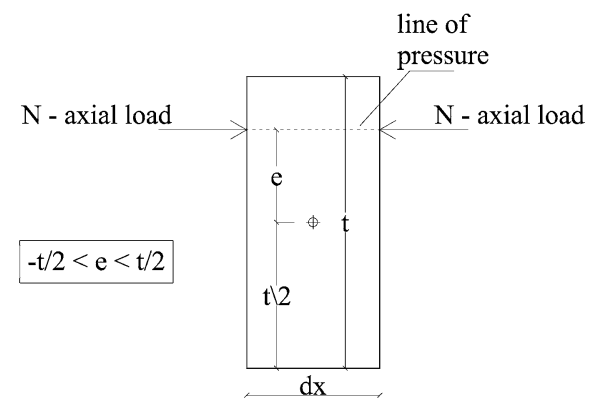

(a)
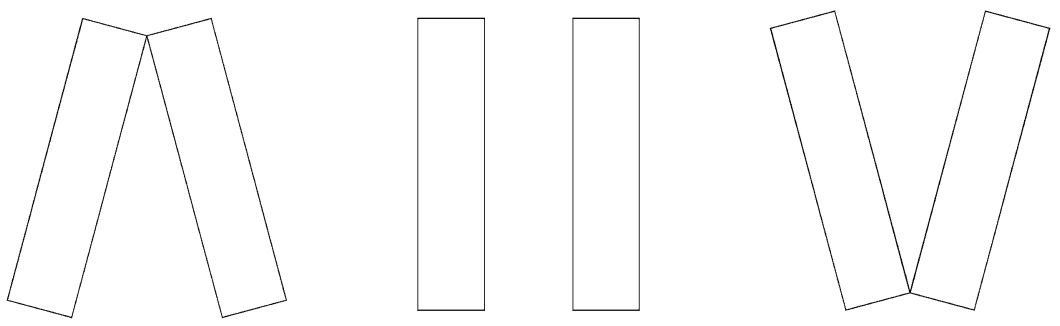

Fig. 1 a Admissible equilibrium state, $\mathbf{b}$ admissible state of deformation 

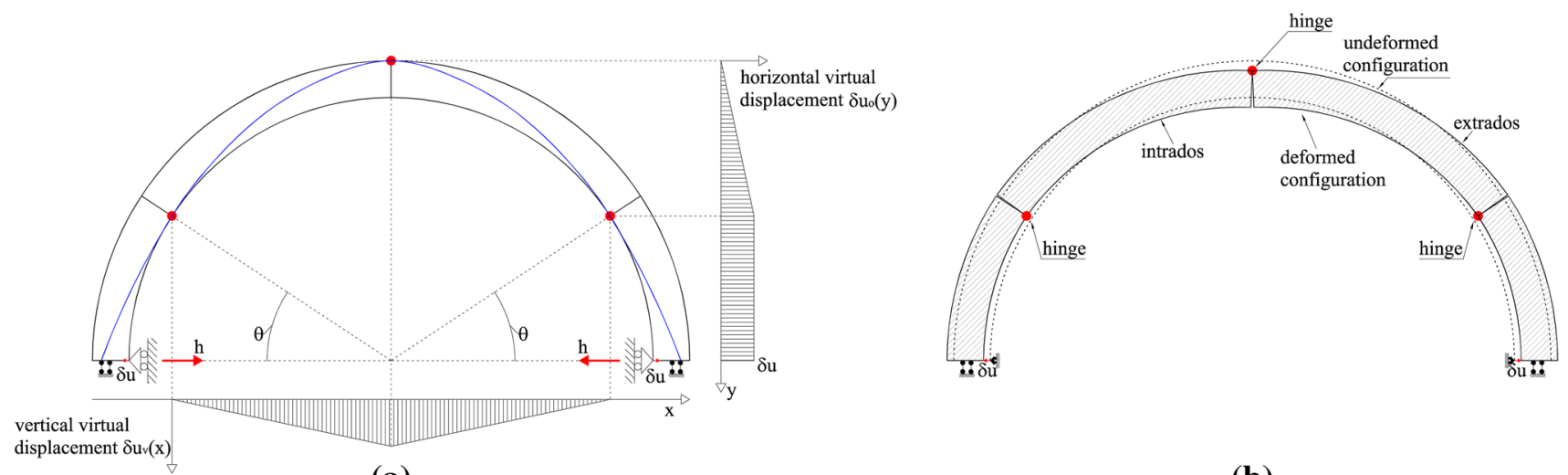

(a)

(b)

Fig. 2 Virtual displacements at the springing: a admissible equilibrium and mechanism, b configuration after the virtual displacement

If the stresses $\sigma$ are admissible, the internal work in Eq. (1) is less than or equal to zero. Since the elastic deformation $\varepsilon(\delta u)$ is assumed as negligible in the body, only the admissible eccentric axial compression load works for the displacement due to the crack opening. This internal work is equal to zero only if the eccentric normal stresses pass through the hinges (crack tips, Fig. 2a). The actual settlement mechanism is defined by a line of pressure passing right through the hinges that define the mechanism.

According to the kinematic theorem (Como 1996), the position of the hinges $\left(x_{i}\right)$ is obtained maximizing Eq. (2), obtained from Eq. (1), by imposing a null value of the internal work:

$\mu\left(x_{i}\right)=-\frac{\left\langle g, \delta u\left(x_{i}\right)\right\rangle}{\left\langle h, \delta u\left(x_{i}\right)\right\rangle}$

For the continuous circular arch, the Eq. (2) can be written as a function of the angle $\theta$ that defines the symmetric position of the intrados hinges (Fig. 2a):

$\mu(\theta)=\frac{4\left(r_{\mathrm{e}}^{3}-r_{\mathrm{i}}^{3}\right)(\operatorname{sen}(\theta)-1)+r_{\mathrm{i}} \cos (\theta)(3 \pi-6 \theta)\left(r_{\mathrm{e}}^{2}-r_{\mathrm{i}}^{2}\right)}{12\left(r_{\mathrm{e}}-r_{\mathrm{i}} \operatorname{sen}(\theta)\right)} \gamma p$

where $r_{\mathrm{i}}$ and $r_{\mathrm{e}}$ are the internal and external radii, respectively, $\gamma$ is the specific weight, and $p$ is the arch width. Therefore, the minimum thrust is

$H_{\text {min }}=\max _{\theta}(\mu(\theta)) \cdot h$

\section{Deformed configuration of the arch after the horizontal displacement at the springing}

The above described procedure is now extended to the case of large displacements. In particular, the limit analysis is applied with reference to the deformed shape of the structure. The generic deformed configuration depends on the value of the support displacements and on the hinge locations, supposed to be always in the joints.

The class of admissible mechanisms considers a symmetric location of hinges with respect to the symmetry axis of the arch. Indeed, if the keystone is present, four hinges can form (two at the extrados in the keystone and two at the intrados in the haunch-Fig. 3a), or three hinges can open if there is no keystone (one hinge at the extrados and two at the intrados-Fig. 3b), in order to accommodate the displacements of the supports.

The search of the deformed configuration is performed through the kinematics of rigid bodies, obtained by assembling the voussoirs localized between two consecutive hinges.

The symmetric mechanism of the arch subjected to a finite horizontal displacement of the supports $(u)$ is shown in Fig. 4, for both arches with and without keystone. The rigid bodies, named 1 and 3 in Fig. 4, are characterized by a rigid translation along the horizontal and vertical direction, respectively, while, the blocks named 2 move with a rigid translation $u$ and a rigid rotation $\varphi$. This rotation and the vertical displacement $v$ of the keystone are determined through the geometric construction of Fig. 4. In particular, the intersection between the vertical straight line passing through the upper hinge and the circle with center in the hinge at the intrados and radius equal to the distance between the two hinges at the edges of the body named 2 is imposed (Fig. 4).

The deformed configurations in the hypothesis of large displacements can be univocally determined once the values of the horizontal displacements of the supports $(u)$ and the positions $x_{i}$ of the internal hinges are known. All the following analyses will be carried out with reference to the arch without the keystone (Fig. 4b), but the same procedure can be adopted for the other cited case (Fig. 4a). 


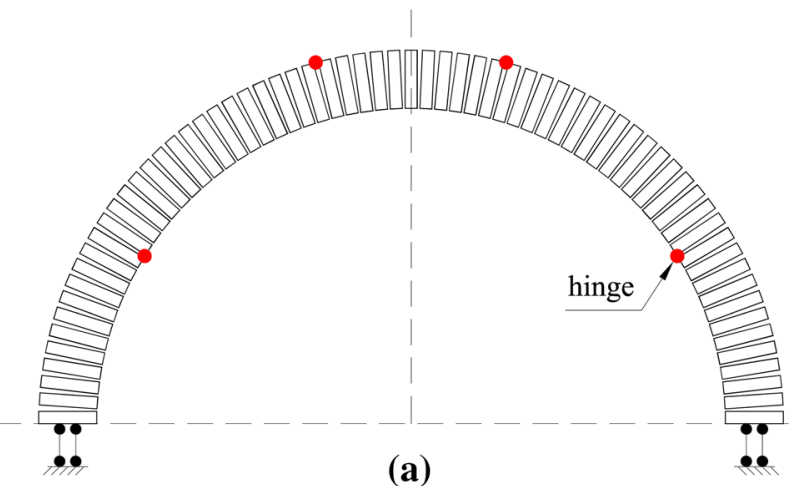

(a)

Fig. 3 Hinge locations: a with keystone, b without keystone

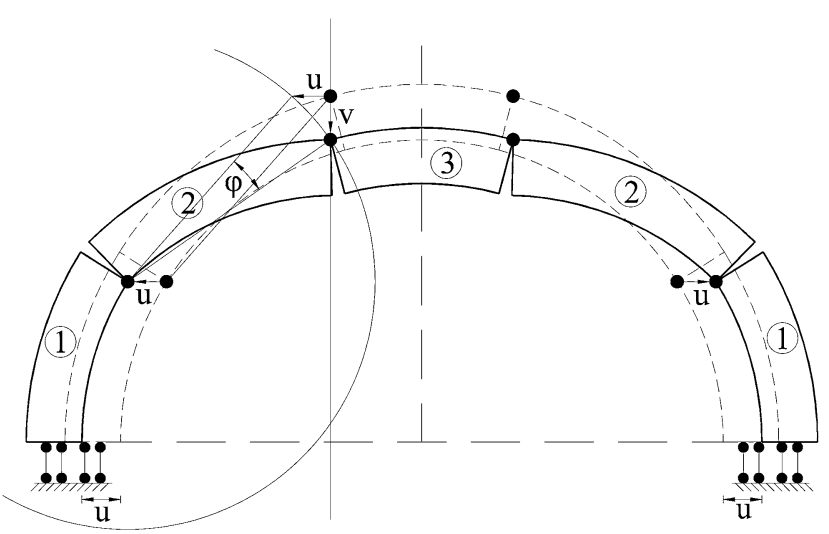

(a)

Fig. 4 Deformed configurations: a with keystone, b without keystone

\section{Hinge location}

In the undeformed configuration, small movements of the supports cause the formation of a three-hinged arch in the central portion of the structure ("State of the art: limit analysis theorems in the undeformed configuration" section). When the displacements of the supports increase, the hinges can move in a different position. This phenomenon can take place only if the internal works of the stresses $\sigma$ for a kinematic virtual displacement $\delta u_{\mathrm{mh}}$, corresponding to the movement of the hinge and reported in Fig. 5a, are equal to zero. The line of pressure is always uniquely determined by the position of the hinges defining the deformed configuration. For a fixed value of the support displacement, if this curve is tangent to another point of the structure (Fig. 5b), then the position of the intrados hinges changes. In this situation, indeed, the internal works of the stresses $\sigma$ for the virtual displacements $\delta u_{\mathrm{mh}}$, corresponding to the closure of the old hinges and opening of the new ones, are equal to zero.

Therefore, the equation of principle of virtual work is

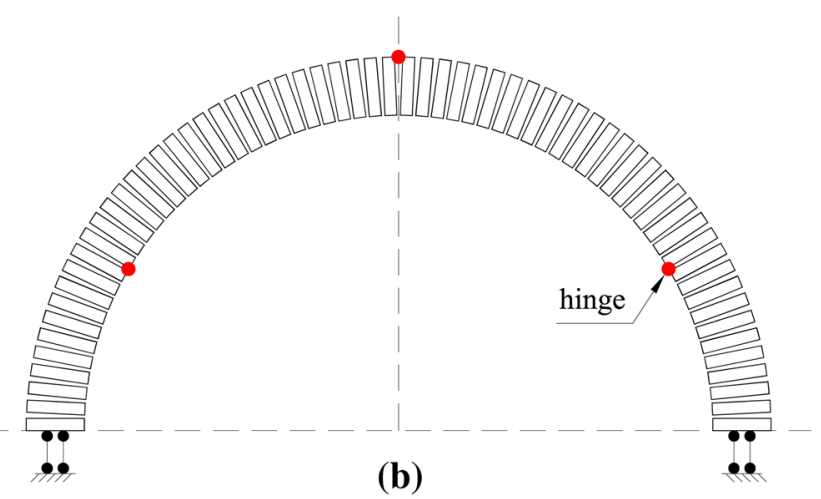

(b)

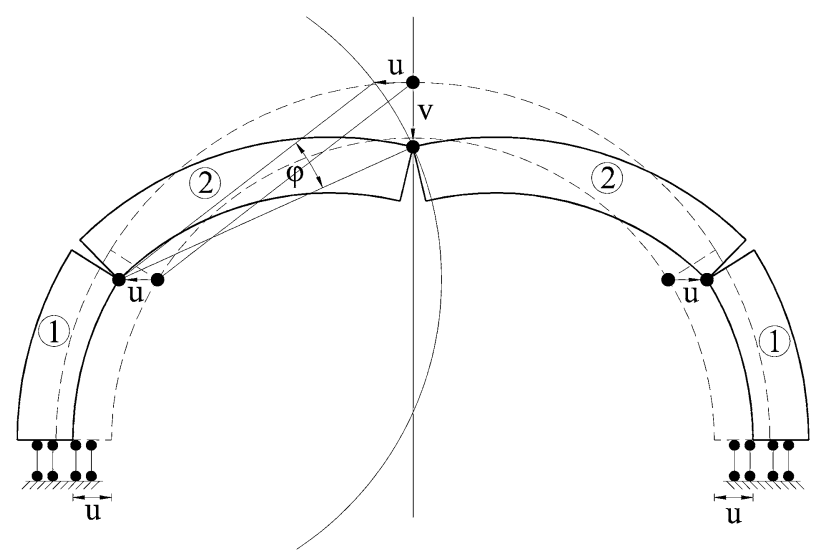

(b)

$\left\langle g(\mathrm{u}), \delta u_{\mathrm{mh}}\left(u, x_{\mathrm{h}}\right)\right\rangle=0 \quad \delta u_{\mathrm{mh}}\left(u, x_{\mathrm{h}}\right) \in M$

where $x_{\mathrm{h}}$ is the position of the new hinge.

The configurations of the arch before and after the movement of the hinge are reported in Fig. 6.

\section{Limit analysis theorems in the deformed configuration}

In the new deformed configuration, the masonry arch can sustain the weight until the line of pressure reaches the extrados at the springing, and two hinges are formed (A and $\mathrm{B}$ in Fig. $7 \mathrm{~b}$ ), giving rise to a collapse mechanism characterized by five hinges.

In the deformed configuration, defined by the support displacement, $u$, the Eq. (6) is necessary and sufficient to guarantee the existence of an admissible equilibrium state:

$\left\langle g\left(u, x_{i}\right), \delta u_{\text {coll }}\left(u, x_{i}\right)\right\rangle \leq 0$

where the generic virtual collapse mechanism $\delta u_{\text {coll }}$ is reported in Fig. 7. 
mechanism corresponding to

the movement of the hinge

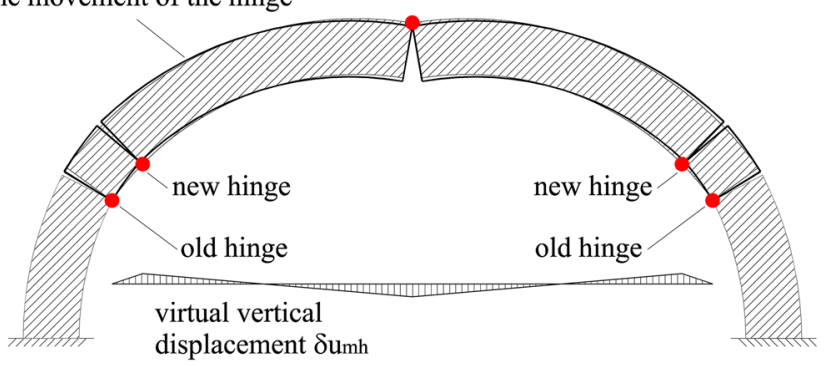

(a)

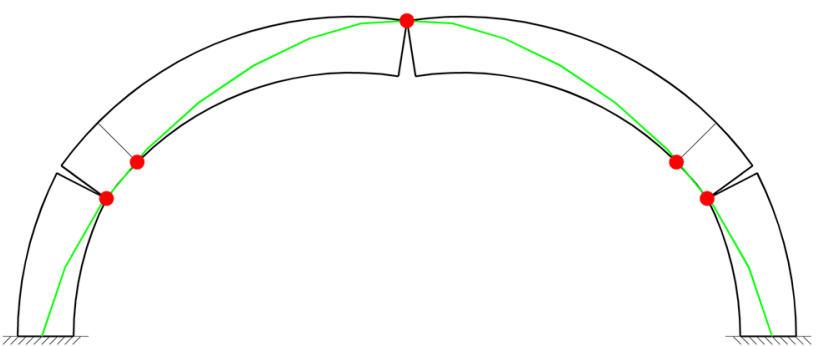

(b)

Fig. 5 Mechanism and line of pressure for the movement of the hinges for a fixed support displacement

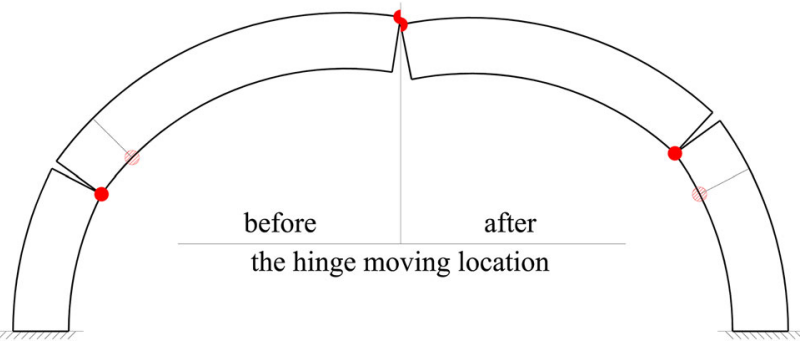

Fig. 6 Deformed configurations before and after the movement of the hinges

The proofs of the conditions of necessity and sufficiency of Eq. (6) in the case of undeformed arch are reported in Como (2013).

To prove the condition of necessity in our case, applied in the deformed configuration with fixed constraints, the principle of virtual work has to be written:

$\left\langle g\left(u, x_{i}\right), \delta u_{\text {coll }}\left(u, x_{i}\right)\right\rangle=\left\langle\sigma\left(u, x_{i}\right), \delta \varepsilon\left(u, x_{i}\right)\right\rangle$

If the stress state is admissible, the internal work should be lower than or equal to zero, and therefore, the inequality (6) must be true.

The proof of the condition of sufficiency must be made assuming, ad absurdum, that under the gravity load $g$, the structure is not in a condition of admissible equilibrium. The virtual displacement and the virtual deformation can be written, respectively, as

$\delta u_{\text {coll }}\left(u, x_{i}\right)=v(t) \mathrm{d} t \quad \delta \varepsilon\left(u, x_{i}\right)=\dot{\varepsilon}(t) \mathrm{d} t$

where $v(t)$ is the speed of the movement.

Taking into account the inertial forces produced in the body due to the acceleration $\dot{v}$ and the Eq. (8), the equation of principle of virtual work becomes

$\left\langle g\left(u, x_{i}\right), v(t)\right\rangle-\langle\rho \dot{v}, v\rangle=\left\langle\sigma\left(u, x_{i}\right), \dot{\varepsilon}(t)\right\rangle$

The kinetic energy of the body and its rate of change are

$T=\frac{1}{2}\langle\rho v, v\rangle \quad \frac{\mathrm{d} T}{\mathrm{~d} t}=\langle\rho \dot{v}, v\rangle$

During the motion, the internal work is equal to zero, and the Eq. (6) becomes

$\left\langle g\left(u, x_{i}\right), v(t)\right\rangle=\frac{\mathrm{d} T}{\mathrm{~d} t}$

The variation of the kinetic energy in the time must be positive since the body begins to move. Then, from Eq. (11) it is obtained that

$\left\langle g\left(u, x_{i}\right), v(t)\right\rangle>0$

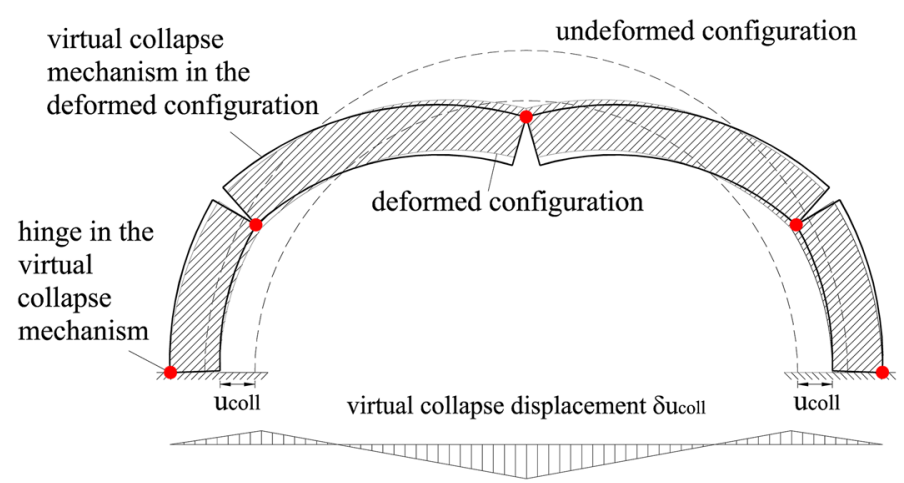

(a)

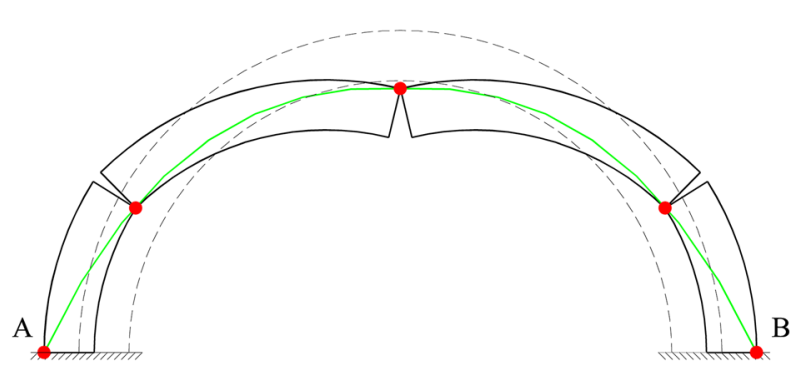

(b)

Fig. 7 Mechanism and line of pressure for the collapse displacement of the arch 
which is in contradiction with the Eq. (6). Consequently, if the Eq. (6) is verified, the body is in an admissible equilibrium.

\section{Collapse displacement}

The collapse displacement $u_{\text {coll }}$ can be evaluated using Eq. (6), i.e., by imposing that the work of gravity load, for the mechanism of Fig. 7, is equal to zero:

$\left\langle g\left(u_{\text {coll }}, x_{i}\right), \delta u_{\text {coll }}\left(u_{\text {coll }}, x_{i}\right)\right\rangle=0$

Therefore, for the displacement $u_{\text {coll }}$, as per the virtual works principle, the internal work is equal to zero:

$\left\langle\sigma\left(u_{\text {coll }}, x_{i}\right), \delta \varepsilon_{\delta u_{\text {coll }}}\left(u_{\text {coll }}, x_{i}\right)\right\rangle=0$,

and the line of pressure is internal to the structure and passes through the hinges (Fig. 7b).

Anyway, for each value of the support displacement $u$, the hinge position has to be checked since a different mechanism can occur. Indeed, if three hinges (in the arch without keystone) are aligned on a straight line (Fig. 8), the structure becomes unstable since the gravitational loads of the central portion of the arch perform positive work for the virtual vertical displacement reported in Fig. 8.

If this geometric condition takes place, the related support displacement is the collapse one and the mechanism of Fig. 7 can be never reached. The whole procedure is summarized in Fig. 9.

\section{Minimum thrust}

In the deformed configuration, the thrust of the arch can be calculated by assuming a virtual horizontal displacement $\delta u$ of the supports, as shown in Fig. 10. The principle of virtual work [Eq. (1), in the undeformed configuration], rewritten in the deformed configuration, becomes

$\left\langle g\left(u, x_{i}\right), \delta u\left(u, x_{i}\right)\right\rangle+\mu_{\mathrm{r}}\left\langle t, \delta u\left(u, x_{i}\right)\right\rangle=\left\langle\sigma\left(u, x_{i}\right), \delta \varepsilon\left(u, x_{i}\right)\right\rangle$

The arch is in a condition of admissible equilibrium, so the line of pressure passes through the hinges, and the internal work is equal to zero. The value of the thrust can be evaluated for each value of the displacement $u$ :

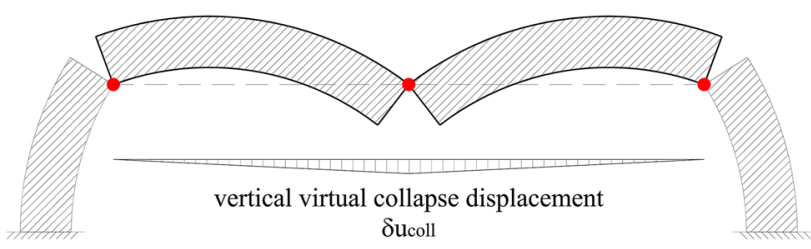

Fig. 8 Collapse displacement for the alignment of the hinges
Fig. 9 Flow chart of the procedure to determine the collapse displacement of an arch on spreading supports

$\mu_{\mathrm{r}}(u)=\frac{\left\langle g\left(u, x_{i}\right), \delta u\left(u, x_{i}\right)\right\rangle}{\left\langle t, \delta u\left(u, x_{i}\right)\right\rangle}$

In the following sections, after the model validation with experimental outcomes, the described procedure is applied to a semi-circular arch. Furthermore, a parametric survey is carried out in order to analyze the influence of the main geometric properties on the minimum thrust and on the ultimate displacement.

\section{Comparison with experimental results}

The developed kinematic model is validated through a comparison with the small-scale test carried out by Ochsendorf (2002). The arch is characterized by 16 voussoirs cast as individual concrete blocks with a $50-\mathrm{mm}$ radial thickness. The mean radius $R$ is equal to $220 \mathrm{~mm}$, and the thickness-radius ratio $(t / R)$ is 0.23 . During the test the intrados hinges opened initially for an angle $\beta=56.25^{\circ}$ (Fig. 11), and did not move at the displacement increasing. The experimental collapse took place for a displacement value of $30 \mathrm{~mm}$ (span increase equal to $15.4 \%$ ). The hinge positions evaluated with the proposed analytic model are in a perfect agreement with the experimental outcome, as shown in Fig. 11. Furthermore, the analytic value of the ultimate displacement is equal to $32.24 \mathrm{~mm}$, related to a span increase of $16.53 \%$. This value is about $6.8 \%$ higher with respect to the measured one. The span increase developed by Ochsendorf with a static procedure, is $16.9 \%$. It is worth highlighting that the proposed kinematic approach, and the static one proposed by Ochsendorf should give the same results (Como 2013). The very small difference (16.53 against $16.9 \%$ ) depends on the approximation in the displacement step value used in the incremental analysis.

The minimum thrusts are evaluated with the proposed kinematic approach in both the undeformed and deformed configurations, from Eqs. (4) and (16), respectively. The minimum thrust in the undeformed configuration is equal to $0.14 \mathrm{~W}$ (where $\mathrm{W}$ is the arch weight), while for the collapse displacement, it is $0.30 \mathrm{~W}$ with an increase of $114 \%$.

\section{Parametric survey}

A parametric survey is carried out in order to analyze the influences of the main geometric parameters on the global response of a semi-circular arch. 
Definition of the geometric characteristics of the arch

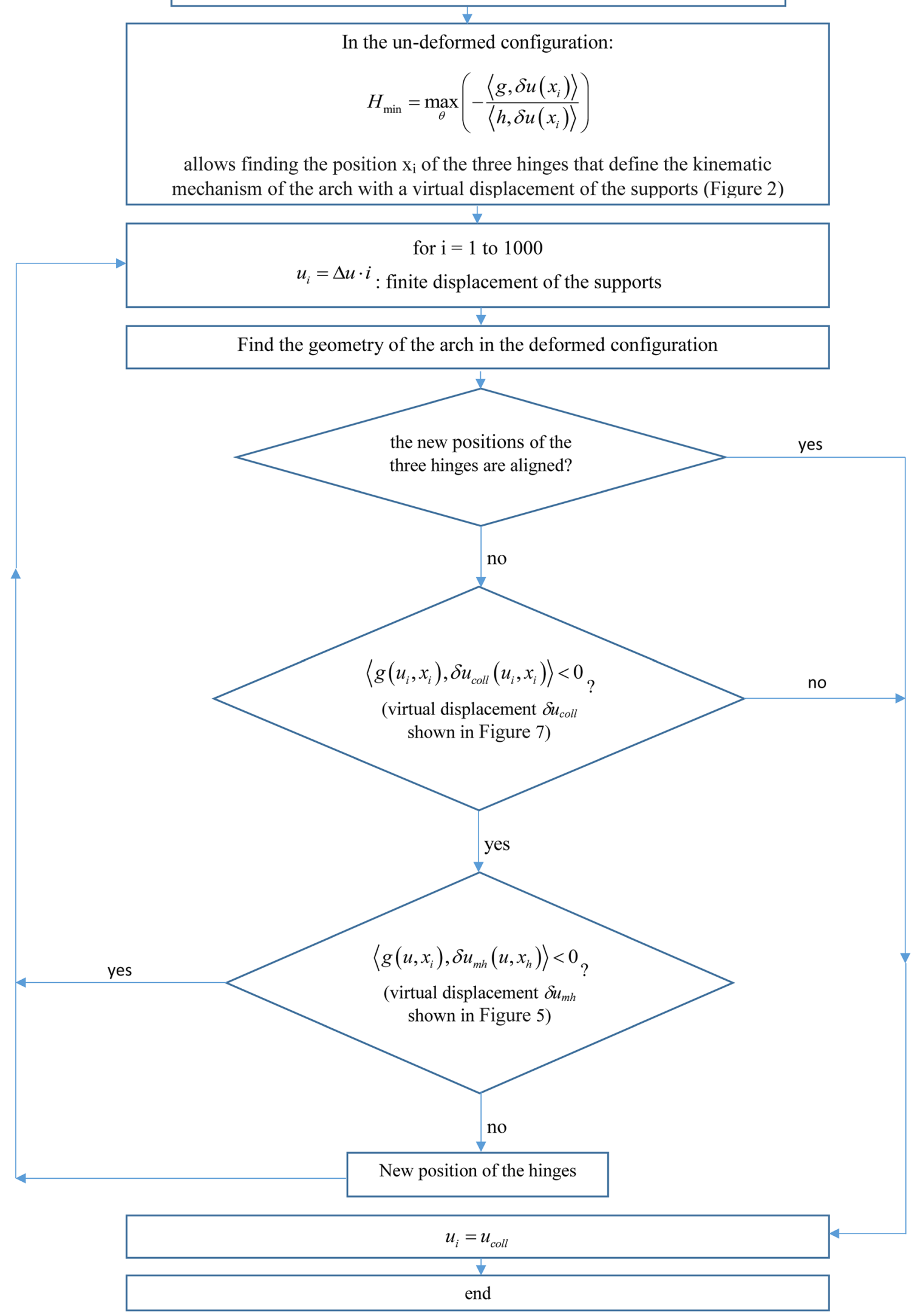




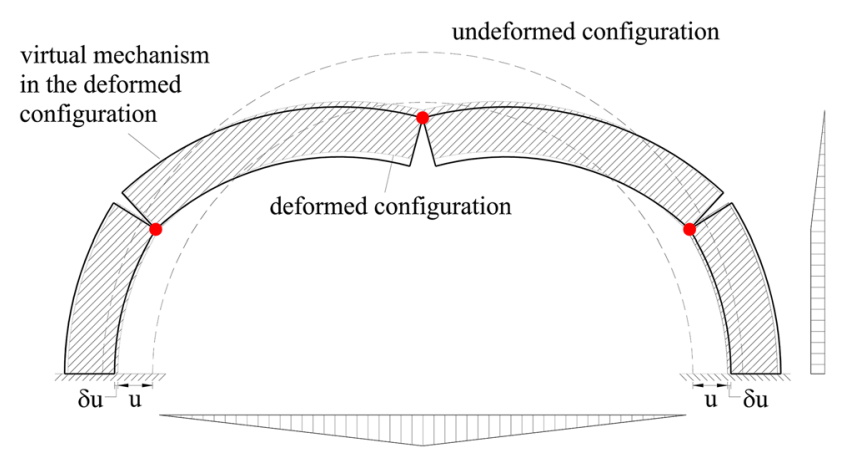

Fig. 10 Mechanism for a virtual displacement of the support in the deformed configuration of the arch

First of all, it will be shown that the main parameter affecting the structural behavior is the ratio between the thickness and the mean radius $(t / R)$. With this as our aim, in Fig. 12, the collapse displacements, expressed in a nondimensional way with respect to the thickness, versus the mean radius, are plotted in the case of an arch with 16 voussoirs (Fig. 12a) and a continuous structure (Fig. 12b). Different values of the $t / R$ have been considered, starting from the minimum literature value equal to 0.11 (Como 2013; Ochsendorf 2002). It can be clearly noted that the nondimensional displacement depends on $t / R$ (and in particular increases with it), while it is practically independent of the mean radius in both the cases.

The same result is obtained for the thrust, expressed in a nondimensional form with respect to the weight, as shown in Fig. 13a for an arch with 16 voussoirs and Fig. 13b for a continuous structure.
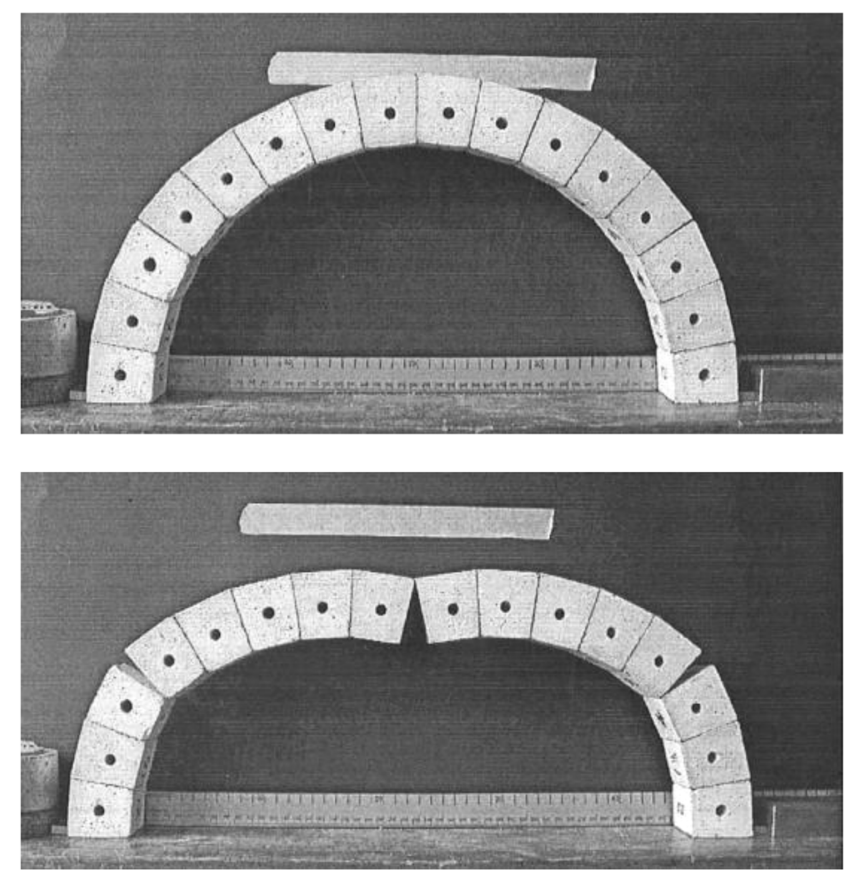

From the above reported results, it can be concluded that the ratio between the thickness and the radius can be assumed as the main parameter affecting the ultimate condition of the arch. For this reason, a parametric survey is carried out, in order to evaluate the influence of $t / R$ on the kinematic (hinge position and collapse displacement) and static (thrust at ultimate displacement) conditions.

\section{Hinge position}

The influences of the $t / R$ ratio on the hinge location at intrados (defined by the angle $\beta$ from the crown) are shown in Fig. 14 for both the deformed and undeformed configurations of a continuous arch.

For both the cases, when the $t / R$ ratio varies, the intrados hinge ( $\beta$, Fig. 14) moves. In particular, it can be noted that the $\beta$ angle increases from about $54^{\circ}$ to $64^{\circ}$ (i.e., the hinge moves toward the support) when $t / R$ increases from 0.11 to about 0.4 , while it decreases (again from $64^{\circ}$ to $54^{\circ}$ ), for higher values of the $t / R$ ratio.

In the deformed configuration, the hinge position at the intrados changes with respect to the undeformed configuration if the $t / R$ parameter is lower than 0.42 , and moves slightly toward the center.

The case of arches with a different number of voussoirs is further considered. In Fig. 15, the hinge position at the intrados is again plotted versus the nondimensional thickness, as a function of the voussoirs number. The behavior of the continuous arch (Fig. 14) is superimposed to the other patterns, with the continuous black line. The
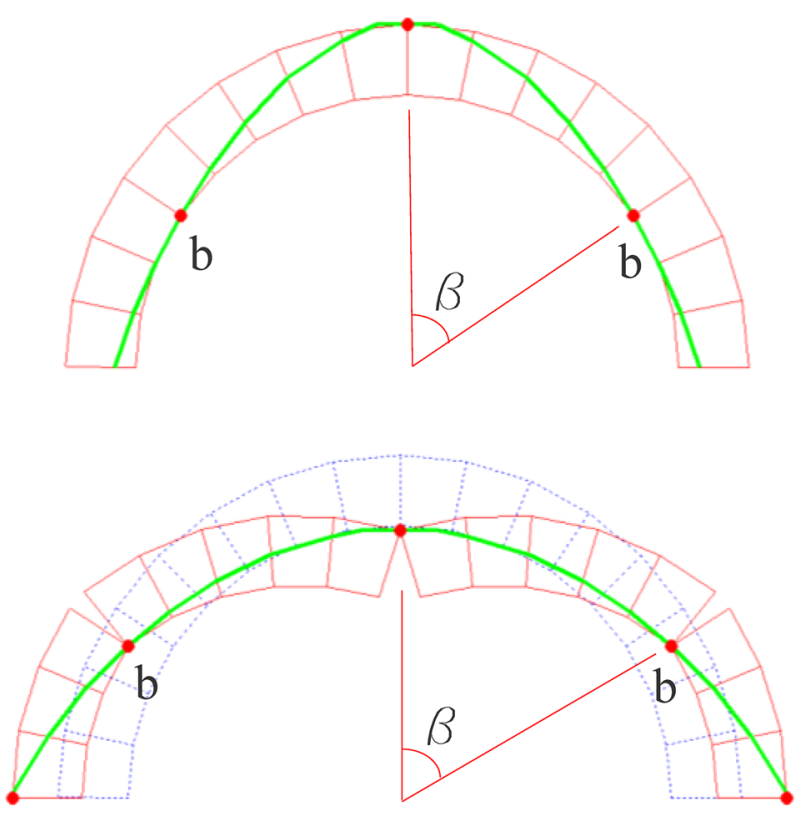

Fig. 11 Comparison with the experimental test carried out by Ochsendorf (2002) 
16 voussoirs

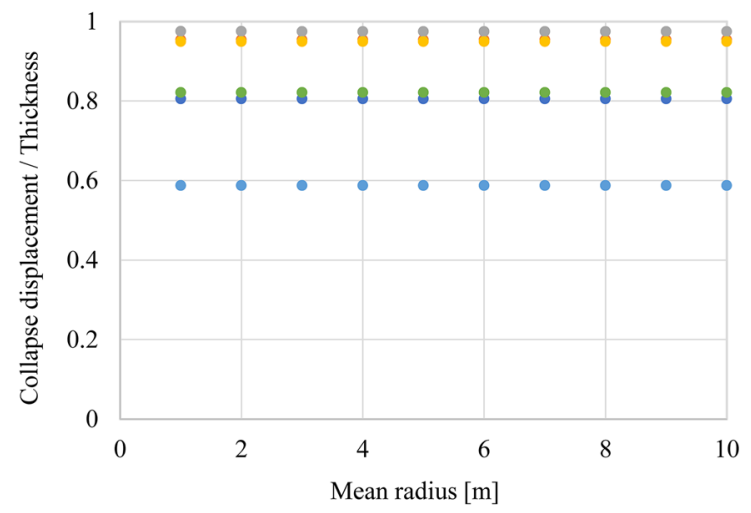

(a)

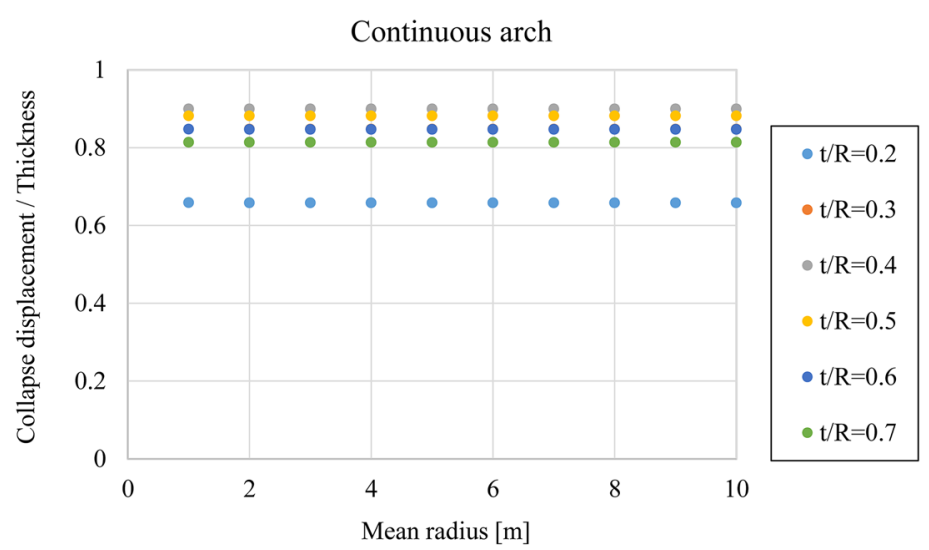

(b)

Fig. 12 Influence of the mean radius on the nondimensional collapse displacement

16 voussoirs

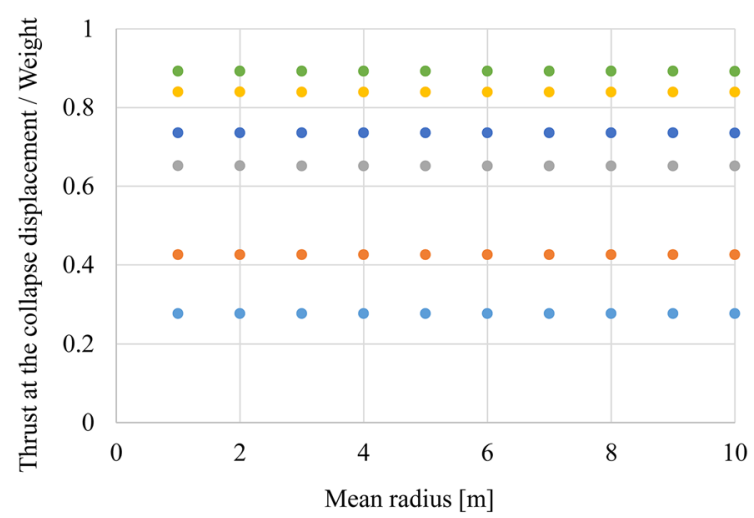

(a)

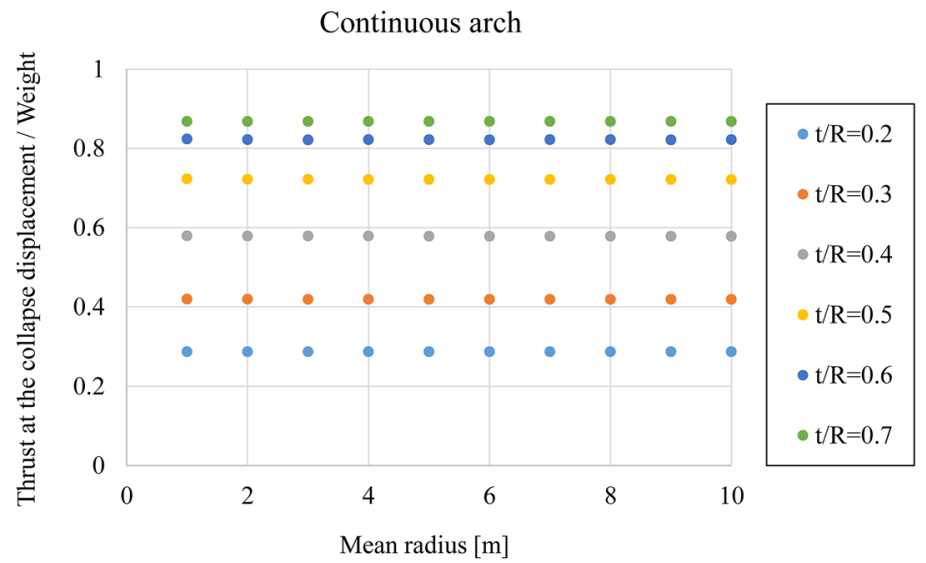

(b)

Fig. 13 Influence of the mean radius on the nondimensional thrust

undeformed configuration is represented in Fig. 15a, while the deformed one is shown in Fig. 15b. The hinge position is obviously, for the assumed hypothesis ("Deformed configuration of the arch after the horizontal displacement at the springing" section) strictly connected to the number of voussoirs. In particular, it can be noted that this angle

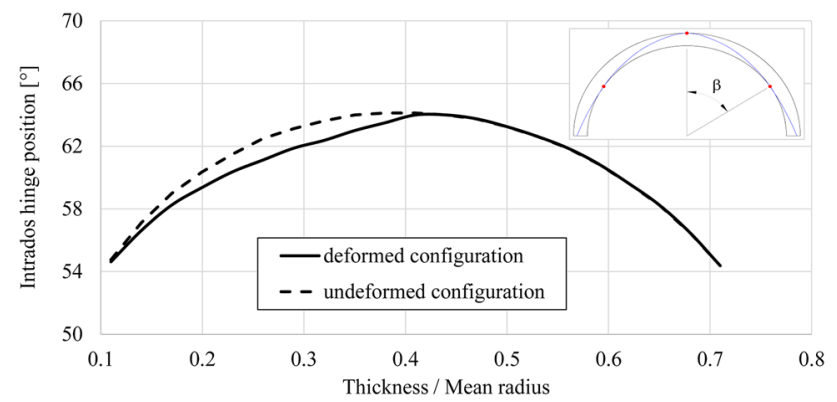

Fig. 14 Influences of $t / R$ on the hinge intrados position $(\beta)$ for a continuous arch can remain fixed in a large ranges of $t / R$ ratios, in both the cases of deformed and undeformed conditions.

\section{Minimum thrust in the undeformed configuration}

The influence of the nondimensional thickness $t / R$ on the minimum thrust $\left(H_{\min }\right)$ is now evaluated, in the hypothesis of arches with different number of voussoirs. The results of the parametric analysis are shown in Fig. 16a, where the thrust is reported in a nondimensional form, divided by the weight of the arch $(W)$. It can be clearly noted that the thrust is practically independent of the voussoirs numbers, and it decreases in nonlinear way when $t / R$ increases.

Finally, a simplified formulation has been obtained through a regression with the ordinary least squares method, based on the analytic outcomes of Fig. 16a

$H_{\min } / W=\left[0.22(t / R)^{2}-0.463(t / R)+0.2383\right]$ 


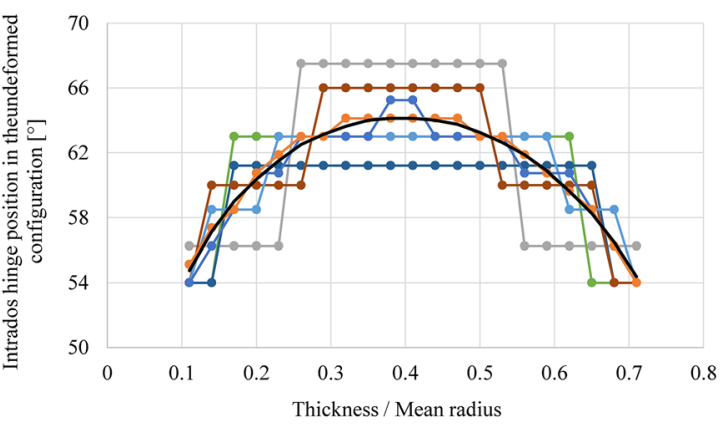

(a)

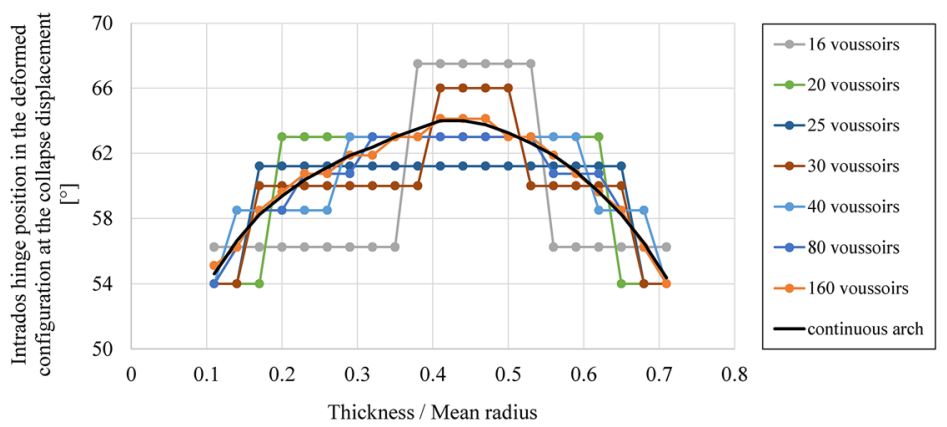

(b)

Fig. 15 Influences of $t / R$ on the hinge intrados position $(\beta)$ for arches with voussoirs; a undeformed configuration; b deformed configuration

The formulation appears really effective, as shown in Fig. 16b where the results from Eq. (17) are compared with the ones obtained with the proposed model. It can be clearly noted that the dots lie on the bisector line.

According to the Eq. (17), it can be stated that when the arch thickness increases, the line of pressure becomes more vertical in the springing. Indeed, in presence of piers or abutments, the possibility of overturning of these elements is lower for thick arches.

\section{Thrust-displacement curves for the arch}

In Fig. 17, the curves of thrust-displacement for the analyzed arches are plotted in a nondimensional form with respect to the relative collapse value. It can be noticed the increase of the slopes occurs when $t / R$ increases.

The variation of the collapse displacement $u_{\text {coll }}$, expressed in a nondimensional form with respect to the thickness $t$, with $t / R$ is shown in Fig. 18a for arches with different number of voussoirs. A significant increase of this parameter occurs for $t / R$ varying between 0.11 and $0.2-0.3$.
Slight variations of $u_{\text {coll }} / t$ take place for higher values of $t /$ $R$. The number of voussoirs influences the collapse displacement mainly when $t / R$ ranges between 0.25 and 0.5 .

Once again, a simplified formulation has been obtained through a regression with the ordinary least squares method, with reference to the analytic outcomes of Fig. 18a:

$$
\begin{aligned}
u_{\text {coll }} / t= & -365.44(t / R)^{6}+1022.5(t / R)^{5}-1167.8(t / R)^{4} \\
& +702.36(t / R)^{3}-238.84(t / R)^{2} \\
& +44.62(t / R)-2.766
\end{aligned}
$$

The nondimensional collapse displacements evaluated with the limit analysis procedure and from Eq. (18) are pointed out in Fig. 18b. It can be noted that all the dots related to the continuous arch are placed on the bisector line, i.e., the results of Eq. (18) practically coincide with the theoretical ones. Nevertheless, the formulation is more effective for a number of voussoirs higher than 25-30.

Finally, the variation of the thrust at the collapse displacement, expressed in a nondimensional form with

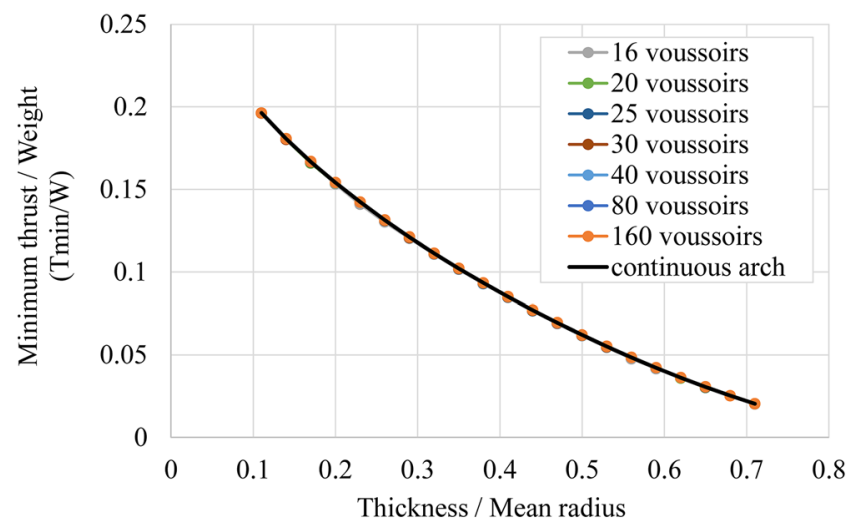

(a)

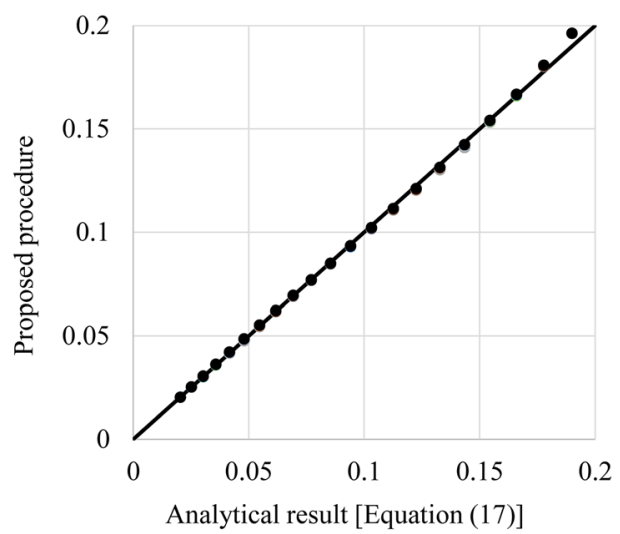

(b)

Fig. 16 a Influence of $t / R$ on the nondimensional minimum thrust in the undeformed condition, b numerical results (limit analysis) versus analytic ones (Eq. 15) 
Fig. 17 Nondimensional thrust-displacement curves for the arch

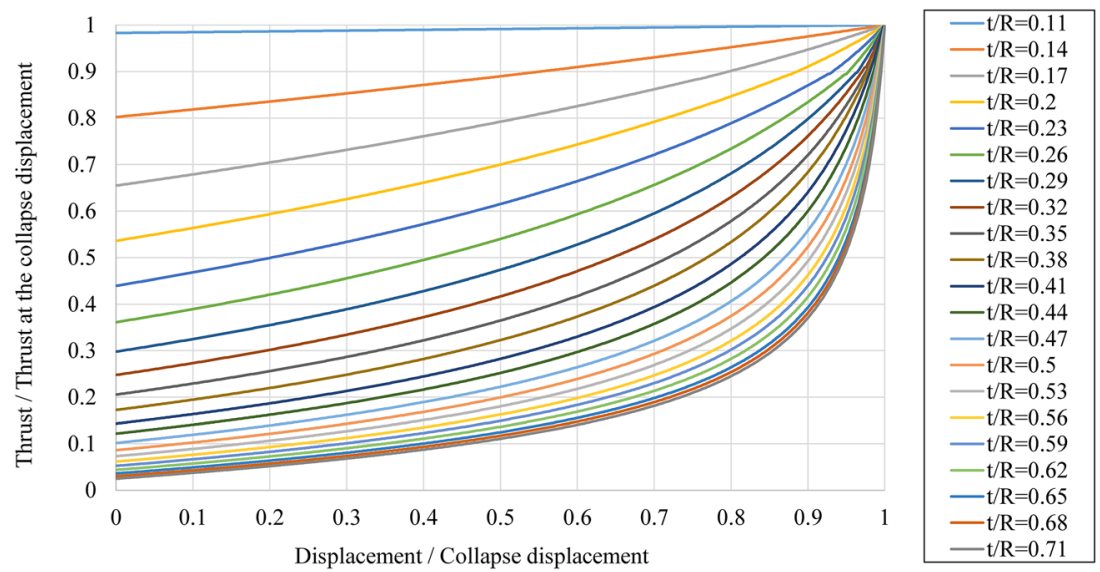

respect to the weight, with $t / R$ is shown in Fig. 19a for arches with different number of voussoirs. A significant increase of this parameter, for $t / R$ varying between 0.11 and 0.55 , can be noted. Slight variations take place for higher values of $t / R$. The number of voussoirs influences the thrust at the collapse displacement, mainly when $t / R$ is higher than 0.35 .

A simplified formulation is developed through a regression with the ordinary least squares method, with reference to the analytic outcomes of Fig. 19a:

$$
\begin{aligned}
H\left(u_{\text {coll }}\right) / W= & -0.21(t / R)^{4}+4.16(t / R)^{3}+4.7(t / R)^{2} \\
& +0.18(t / R)+0.17
\end{aligned}
$$

The nondimensional thrusts obtained with the limit analysis procedure and from Eq. (19) are pointed out in Fig. 19b. Again in these cases, the dots are placed on the bisector line, mainly for voussoirs number higher than 25-30.

\section{The masonry arch on spreading supports}

The proposed model is finally applied to a typical case of a masonry arch on spreading-induced supports, subjected to the gravity load.

In this situation, the global failure condition can be governed by the arch or by the column, as a consequence of the arch thrust and of the springing displacement. In particular, the arch behavior and its collapse displacement can be evaluated as proposed above. The column is subjected, besides the vertical load equal to the weight, to the horizontal out-of-plane action, equal to the arch thrust. Out-ofplane bending due to axial load eccentricity and lateral loads have a strong impact on the stability of masonry members. Yokel (1971) has developed a solution for the deflection and stability of compressed members made with no-tension materials and elastic behavior in compression. Schultz and Mueffelman (2003) have improved Yokel's model by adding the out-of-plane bending. Figure 20 shows the geometric characteristics of the column, the

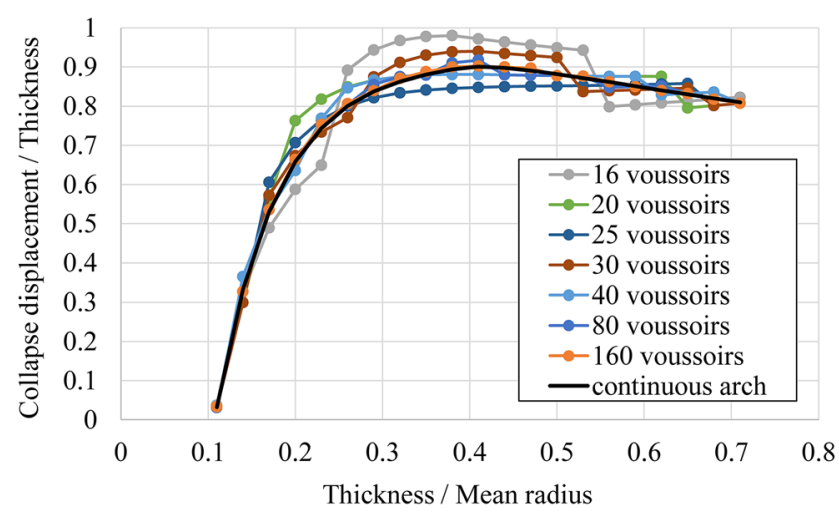

(a)

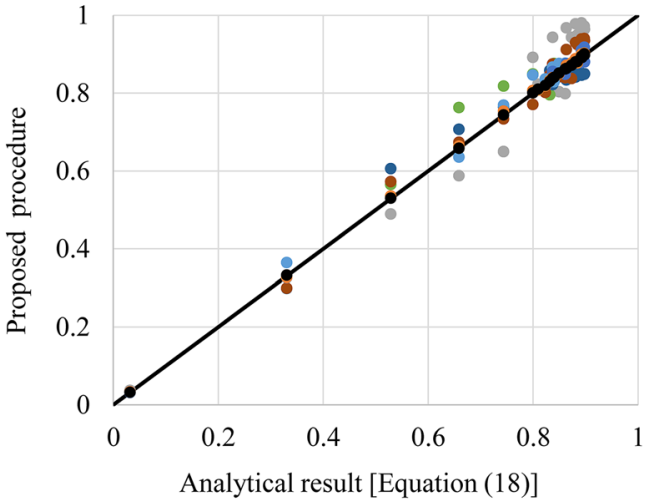

(b)

Fig. 18 Influence of $t / R$ on the nondimensional collapse displacement in the deformed condition: numerical results (limit analysis) versus analytic ones (Eq. 16) 


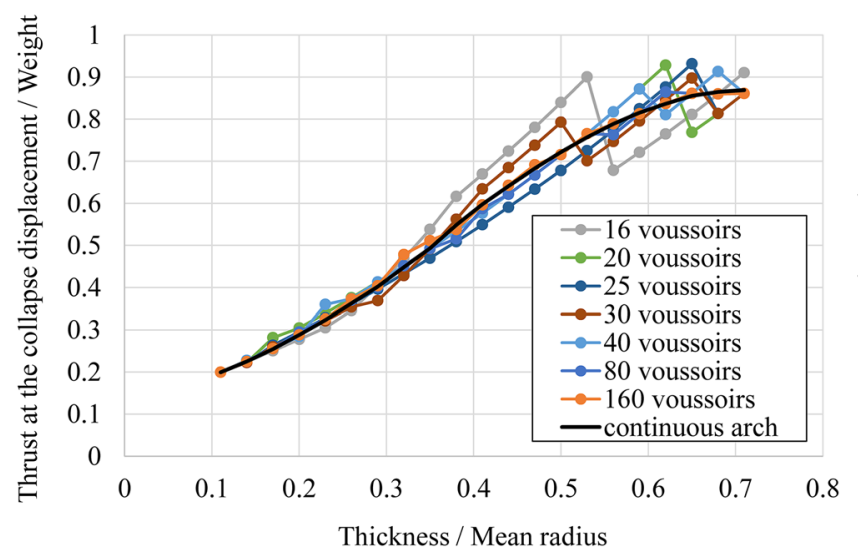

(a)

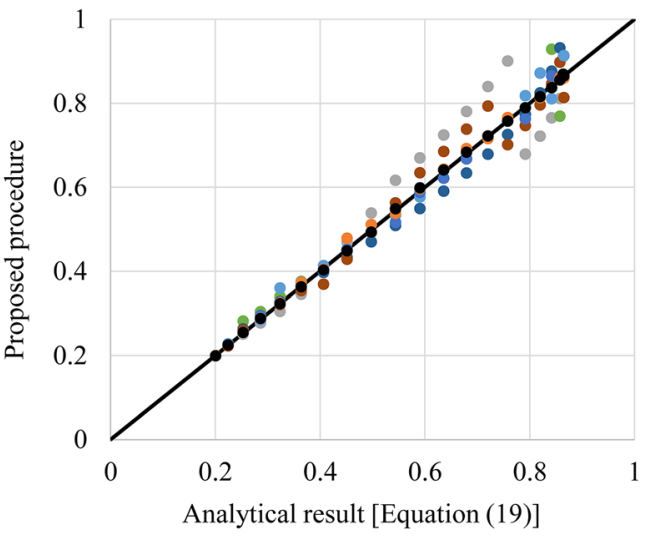

(b)

Fig. 19 Influences of $t / R$ on the nondimensional thrusts at collapse displacement: numerical results (limit analysis) versus analytic ones (Eq. 17)

reference system $X Y$ centered in the compressed edge of the base section and the vertical and horizontal loads, named $P$ and $H$, respectively. The uncracked and cracked zones of the column are also shown, together with the stress distribution on the generic cross section.

The authors evaluate the displacement of the column through the solution of the differential equation:

$\frac{\mathrm{d}^{2} y}{\mathrm{~d} x^{2}}=\frac{\frac{2 P}{9 E b}}{\left[u_{o}+y(x)-\frac{M(x)}{P}\right]^{2}}$

where $E$ is the Young's modulus, $b$ is the member width, and $M(x)$ is the bending moment function.

As an example, for the structure with an arch characterized by $t / R=0.11$, by assuming a Young's modulus of $3000 \mathrm{MPa}$, lateral load (shear)-displacement diagrams are constructed and plotted in Fig. 21, for different column heights. In order to analyze the global behavior, the thrustdisplacement relationship shown in Fig. 17 for the arch characterized by the ratio $t / R$ being equal to 0.11 , modified in a dimensional form, is superimposed in Fig. 21.

If the curves related to the behavior of the columns and of the arch intersect themselves, an equilibrium condition can be found; otherwise, the collapse of one of the two members takes place.

When the height of the piers $(H)$ ranges between 3 and $6 \mathrm{~m}$, a point of equilibrium, shown with a red circle, is found as intersection between the shear-displacement curve of the pier and the thrust-displacement curve of the arch. When $H$ is higher than six, the two curves do not intersect, and no equilibrium condition exists. In this case, two collapse modes can be achieved. In particular, if the arch collapse thrust (highlighted by the black cross in Fig. 21) is lower than the maximum load bearable by the piers (represented with the dashed line), the arch governs the failure of the system. This situation takes place, in our case, for heights equal to 7 ,

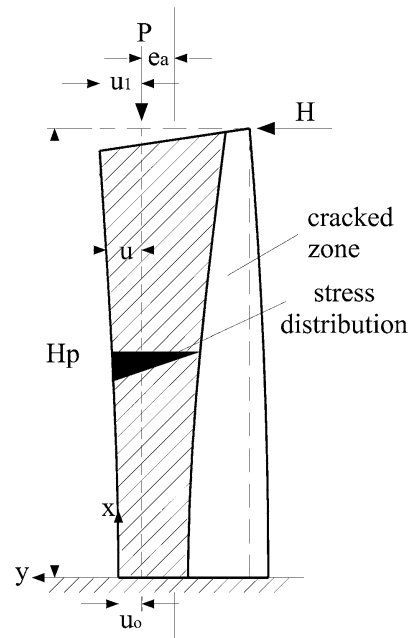

Fig. 20 Deflected shape of the pier

8 , and $9 \mathrm{~m}$ (Fig. 21). On the contrary, the collapse is due to the piers when their maximum load is smaller than the arch collapse thrust ( $H=10$, Fig. 21).

Finally, the above discussed results are compared in Table 1 with the ones obtained with a classical limit analysis, i.e., without considering the abutment displacement. The importance of accounting for this parameter, mainly for high columns, can be clearly noted. As a matter of fact, in the analyzed case, while the classical limit analysis application leads always to a verified structure, this is not the case if the abutment displacements are considered.

\section{Conclusion}

In this paper, the static of masonry arches when a finite displacement at the springing occurs has been analyzed according to the approach of the kinematic theorem of the collapse state. 


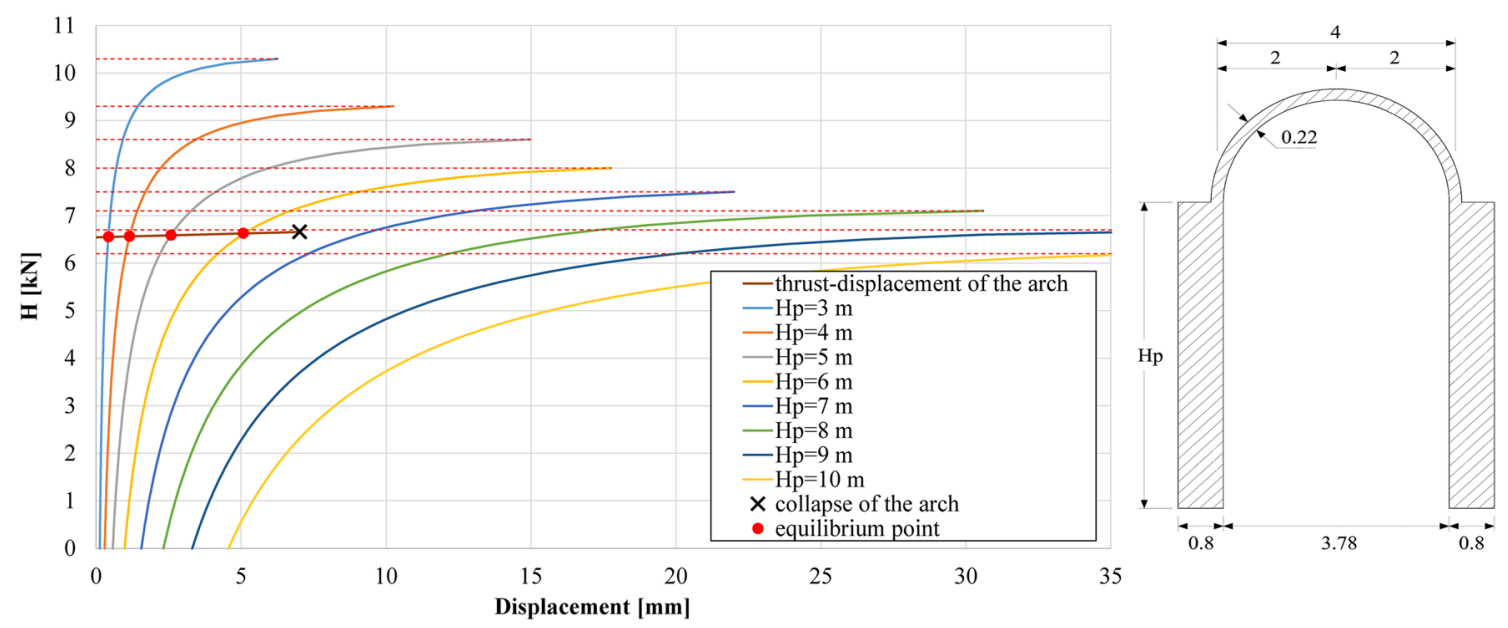

Fig. 21 Lateral load (shear)-displacement curves of the pier, thrust-displacement curve of the arch analyzed

Table 1 The masonry arch on spreading abutment

\begin{tabular}{|c|c|c|c|c|c|c|c|c|}
\hline$t / R$ & \multicolumn{8}{|l|}{0.11} \\
\hline Span & \multicolumn{8}{|c|}{$3.78 \mathrm{~m}$} \\
\hline$H_{\text {pier }}$ & 3 & 4 & 5 & 6 & 7 & 8 & 9 & 10 \\
\hline$B_{\text {pier }}$ & \multicolumn{8}{|l|}{$0.8 \mathrm{~m}$} \\
\hline $\begin{array}{l}\text { Weight of the arch } \\
\text { on the pier }\end{array}$ & \multicolumn{8}{|c|}{$16.59 \mathrm{~m}$} \\
\hline$e_{\mathrm{arc}}$ & \multicolumn{8}{|c|}{$-0.18 \mathrm{~m}$} \\
\hline Weight of the pier & 57.6 & 76.8 & 96 & 115.2 & 134.4 & 153.6 & 172.8 & 192 \\
\hline Minimum thrust $(\mathrm{kN})$ & 6.30 & & & & & & & \\
\hline $\begin{array}{l}\text { Stabilizing moment Ms } \\
(\mathrm{kN} \mathrm{m})\end{array}$ & 32.66 & 40.34 & 48.02 & 55.70 & 63.38 & 71.06 & 78.74 & 86.42 \\
\hline $\begin{array}{l}\text { Overturning moment Mo } \\
(\mathrm{kN} \mathrm{m})\end{array}$ & 18.91 & 25.22 & 31.52 & 37.83 & 44.13 & 50.43 & 56.74 & 63.04 \\
\hline Ms/Mo & 1.73 & 1.60 & 1.52 & 1.47 & 1.44 & 1.41 & 1.39 & 1.37 \\
\hline $\begin{array}{l}\text { Collapse in the proposed } \\
\text { model? }\end{array}$ & No & No & No & No & $\begin{array}{l}\text { Yes, collapse in } \\
\text { the arch }\end{array}$ & $\begin{array}{l}\text { Yes, collapse in } \\
\text { the arch }\end{array}$ & $\begin{array}{l}\text { Yes, collapse in } \\
\text { the arch }\end{array}$ & $\begin{array}{l}\text { Yes, collapse in the } \\
\text { piers }\end{array}$ \\
\hline
\end{tabular}

As the displacements of the supports increase, the hinges are not considered fixed, but can move in a different position toward the crown, closing without energy dissipation and opening again in a new location. A parametric analysis has been carried out in order to evaluate the influence of the geometric parameters on the collapse displacement and on the relative thrust, and it is shown that the ratio between the thickness and the mean radius $(t / R)$ plays a fundamental role.

Furthermore, analytic formulations of the maximum admitted displacement and the related thrust value for the case of the circular arch, calibrated with the results of the proposed model, have been suggested. The main results can be summarized as follows:

- the collapse displacement increases substantially for $t / R$ varying between 0.11 and $0.2-0.3$ and slightly for higher values;
- the thrust rises greatly with the displacement, even up to five times higher than the initial minimum thrust in the ordinary range of $t / R$. The thrust at the collapse displacement increases for $t / R$ varying between 0.11 and 0.55 ; slight variations takes place for higher values of $t / R$;

- the number of voussoirs influences both the displacement and the thrust at the failure condition because of variation of position of the hinges and the resulting changes in geometry, mainly for high value of $t / R$. The minimum thrust in the undeformed configuration is practically independent of the voussoirs' numbers, and it decreases in a nonlinear way when $t / R$ increases.

Finally, a practical application of the proposed model to a masonry arch on spreading abutment, subjected to the gravity load, is provided, in order to highlight the failure 
modes and to remark the cases in which the springing displacements need to be considered.

Open Access This article is distributed under the terms of the Creative Commons Attribution 4.0 International License (http://crea tivecommons.org/licenses/by/4.0/), which permits unrestricted use, distribution, and reproduction in any medium, provided you give appropriate credit to the original author(s) and the source, provide a link to the Creative Commons license, and indicate if changes were made.

\section{References}

Block P, Ochsendorf J (2007) Thrust network analysis: a new methodology for three-dimensional equilibrium. J Int Assoc Shell Spat Struct 48(3):167-173

Coccia S, Como M (2015) Minimum thrust of rounded cross vaults. Int J Archit Herit 9(4):468-484

Coccia S, Como M, Di Carlo F (2015) Wind strength of gothic cathedrals. Eng Fail Anal 55:1-25

Como M (1992) Equilibrium and collapse analysis of masonry bodies. Meccanica 27:185-194

Como M (1996) On the role played by Settlements in the statics of masonry structures. In: The conference on geotechnical engineering for the preservation of monuments and historic sites, Napoli, Italy, October, Balkema, Rotterdam, pp 3-4

Como M (1998) Minimum and maximum thrust states in Statics of ancient masonry buildings. In: Sinopoli A (ed) Proceedings of the 2nd international arch bridge conference, Venice, Italy, October, Balkema, Rotterdam, pp 6-9

Como M (2013) Statics of historic masonry constructions. Springer, New York

D'Ayala DF, Tomasoni E (2011) Three-dimensional analysis of masonry vaults using limit state analysis with finite friction. Int $\mathrm{J}$ Archit Herit 5(2):140-171

Heyman J (1966) The stone skeleton. Int J Solids Struct 2(2):249-256

Heyman J (1995) The stone skeleton: structural engineering of masonry architecture. Cambridge University Press, Cambridge

Huerta S (2008) The analysis of masonry architecture: a historical approach. Archit Sci Rev 51(4):297-328

O'Dwyer DW (1999) Funicular analysis of masonry vaults. Comput Struct 73:187-197

Ochsendorf JA (2002) Collapse of masonry structures. Dissertation, Cambridge University Department of Engineering, Cambridge

Ochsendorf JA (2006) The masonry arch on spreading supports. Struct Eng Inst Struct Eng Lond 84(2):29-36

Romano A, Ochsendorf JA (2010) The mechanics of gothic masonry arches. Int J Archit Herit 4(1):59-82

Schultz AE, Mueffelman JG (2003) Elastic stability of URM walls under transverse loading. TMS J 21(1):31-40

Smars P (2000) Etudes sur la stabilité des arcs et voûtes, confrontation des méthodes de l'analyse limite aux voûtes gothiques du Brabant. Dissertation, Catholic University in Leuven, Belgium

Yokel FY (1971) Stability and load capacity of members with no tensile strength. J Struct Div 97(7):1913-1926 